\title{
Thromboxane Receptor Blockade (SQ 29,548) in Group B Streptococcal Toxin Challenge in Young Lambs ${ }^{1}$
}

\author{
KENNETH SANDBERG, ${ }^{2}$ KARL ERIK EDBERG, ${ }^{2}$ WENDY FISH ${ }^{3}$ ROBERT A. PARKER, \\ CARL HELLERQVIST, AND HÅKAN SUNDELL \\ Departments of Pediatrics /K.S., K.E.E., I'.F., H.S.J, Biochemistry/C.H.J, and Preventive Medicine /R.A.P.J, \\ Vanderbilt University School of Medicine, Nashville. Tennessee 37232
}

\begin{abstract}
Early-onset neonatal group B $\beta$-hemolytic streptococcus (GBS) infection exhibits pathophysiologic characteristics of a toxic shock syndrome, in which a cascade of inflammatory mediators are involved. Thromboxane $\mathrm{A}_{2}\left(\mathrm{TXA}_{2}\right)$ is thought to play an important role as a mediator of the pulmonary response to GBS toxin, because high lung lymph concentrations of a $\mathrm{TXA}_{2}$ metabolite have been observed after GBS toxin injections in sheep. The aim of this study was to evaluate the effects of a selective antagonist of the $\mathrm{TXA}_{2}$-prostaglandin endoperoxide receptor (SQ 29,548). Six unanesthetized young lambs, each serving as its own control, were given SQ 29,548 or vehicle control followed by GBS toxin challenge. Hemodynamic and lung function (lung mechanics, lung volume, ventilation) responses were followed for $5 \mathrm{~h}$. When compared with the control studies, treatment with $S Q$ 29,548 significantly altered the response to GBS toxin. SQ 29,548 reduced the increase in pulmonary and systemic vascular resistance, improved cardiac output and stroke volume, improved dynamic lung compliance but not airway resistance, and improved oxygenation. The attenuating effect of SQ 29,548 was most pronounced during the first phase of toxin response (15-90 $\mathrm{min}$ after toxin infusion), but significant treatment effects were also seen during the second phase (120-300 min after toxin infusion). This study demonstrates that $\mathbf{T X A}_{2}$ is an important mediator of the response to GBS toxin and is responsible for hemodynamic and lung function changes. Thromboxane receptor blockade may offer a potential therapeutic approach to infants with severe early-onset GBS sepsis. (Pediatr Res 35: 571-579, 1994)
\end{abstract}

\section{Abbreviations}

$\mathrm{C}_{\mathrm{dyn}}$, dynamic compliance

CO, cardiac output

CVP, central venous pressure

FRC, functional residual capacity

GBS, group B $\beta$-hemolytic streptococcus

MSP, mean systemic pressure

NC, nitrogen clearance

$\mathbf{P}_{\mathrm{Cw}}$, capillary wedge pressure

Received April 6. 1993; accepted December 13, 1993

Correspondence: Hakan W. Sundell, M.D., Professor of Pediatrics, Vanderbilt

University Medical School, U-1212. MCN, Nashville, TN 37232-2585.

Supported by grants from the March of Dimes $(1-1082)$ and the National Institutes of Health (HL 14214). Drs. Edtherg and Sandberg were partly supported by the Swedish Medical Research Council (Project No. 5703).

'Presented in part at the annual meeting of the Society for Pediatric Research Baltimore, MD, 1992

${ }^{2}$ Current address: Östrasjukhuset, S-41685 Göteborg, Sweden.

${ }^{3}$ Current address: Baptist Hospital, Nashville, TN 37236.
PG, prostaglandin

$P_{L A}$, left atrial pressure

$P_{P A}$, pulmonary arterial pressure

PVR, pulmonary vascular resistance

$R_{\mathrm{l}}$, lung resistance

TX, thromboxane

Early-onset infection by GBS in the newborn infant is still a potentially life-threatening condition with high mortality (1). This disease is characterized by severe respiratory distress, pulmonary hypertension, lung injury with increase in pulmonary capillary permeability, lung edema, progressive respiratory failure, circulatory collapse, and death $(2,3)$. Early-onset GBS infection exhibits pathophysiologic characteristics of a toxemic shock syndrome, in which a cascade of different inflammatory mediators such as prostaglandins, platelet-activating factor, protease, oxygen radicals, and cytokines are engaged (4). An exotoxin from culture medium of GBS type III obtained from infants with early-onset GBS infection has been isolated and characterized as the agent primarily involved in this condition $(5,6)$. GBS toxin is a polysaccharide with an approximate molecular mass of 200000 D. Previous studies have suggested that mannosyl phosphodiester groups constitute functionally active sites on the toxin and that, when injected into sheep, GBS toxin accumulated predominately in the lung (7). Intravenous infusion of picomole amounts of GBS toxin has been shown to induce inflammation also in tumor neovasculature in mice, which like humans are susceptible to GBS as neonates (8).

The isolation of the GBS toxin has made it possible to develop an animal model to study the pathophysiologic events in this disease. This has previously been done by our group in both sheep $(9,10)$ and young lambs $(2,10-12)$. A biphasic response to the toxin has been found. During the first phase, there is increased lung resistance, decreased dynamic lung compliance, increased ventilation, hypoxemia, pulmonary hypertension, and fever. The second phase is characterized by less prominent changes in these variables together with increased lung lymph protein clearance compatible with increased vascular permeability. An increase in lung lymph concentration of $\mathrm{TXB}_{2}$, which is a stable metabolite of TXA toxin reaction $(13,14)$. Preventing $\mathrm{TXA}_{2}$ formation by indomethacin abolished pulmonary hypertension during the first phase, implying that $\mathrm{TXA}_{2}$ might be one of the mediators responsible for the severe hemodynamic and lung function changes seen in the GBS toxic shock syndrome (13).

The advantage of using a bolus injection of GBS toxin as done in our lamb model is that it makes it possible to better study the different pathophysiologic components participating in the GBS 
sepsis reaction. In fulminant human sepsis or in animal models using infusion of GBS bacteria, all these pathophysiologic events are going on at the same time, because it can be suspected that there is a continuous production of toxin by the GBS bacteria.

The aims of this study were to perform a comprehensive determination of the role of $\mathrm{TXA}_{2}$ as a mediator of the GBS toxin response and to test the potential pharmacologic effects of a selective antagonist of the $\mathrm{TXA}_{2}$-prostaglandin endoperoxide receptor, $\{1 S-[1 \alpha, 2 \beta(5 Z), 3 \beta, 4 \alpha]\}-7-[3-(\{2-[($ phenylamino $)$ carbonyl $]-$ hydrazino (methyl)-7-oxabicyclo(2.2.1)hept-2-yl]-5-heptenoic acid (SQ 29,548) (15), during GBS toxin challenge in the unanesthetized young lamb model. The study was designed to investigate the interrelationship between ventilatory and circulatory pathophysiology leading to respiratory insufficiency in GBS sepsis in a way not previously done.

\section{MATERIALS AND METHODS}

Animal preparation. Six full-term lambs were instrumented 1 to $2 \mathrm{wk}$ after birth. Polyvinylchloride catheters $(1.0 \mathrm{~mm}$ inner diameter, $1.8 \mathrm{~mm}$ outer diameter) were placed in a femoral artery and a tarsal vein. A catheter was also placed in the right atrium via the right brachial vein for measurement of CVP. Through a left thoracotomy, catheters were inserted directly into the main pulmonary artery and left atrium, and an electromagnetic flow cuff ( $C$ and $C$ Instruments, Culver City, $C A)$ for measurement of $\mathrm{CO}$ was placed around the main pulmonary artery. The lambs were then allowed to recover for an average of 3 to $4 \mathrm{~d}$, after which two pleural balloons (Silastic envelopes) for measurement of pleural pressure were placed in the right pleural space through a small thoracotomy. A tracheostomy was performed and a Swan-Ganz sheath was placed in an external jugular vein. After the operations, all lambs received gentamicin $(6 \mathrm{mg} / \mathrm{kg} / \mathrm{d})$ and carbenicillin $(150 \mathrm{mg} / \mathrm{kg} / \mathrm{d})$ during the whole study period. Lambs were allowed to recover for 3 to $4 \mathrm{~d}$ before the first study was performed. The second study was performed 4 to $5 \mathrm{~d}$ later.

The average age of the lambs was $22 \mathrm{~d}$ (range 18-28 d) during the control study and $23 \mathrm{~d}$ (range 17-37 d) during the SQ 29,548 study. Their mean weight was $8.9 \mathrm{~kg}$ (range $5.9-12.0 \mathrm{~kg}$ ) during the control study and $8.7 \mathrm{~kg}$ (range $6.6-10.9 \mathrm{~kg}$ ) during the $S Q$ 29,548 study.

Experimental protocol. Six paired GBS toxin experiments were performed in alternating order, with each lamb serving as its own control. The unanesthetized lambs were standing and spontaneously breathing air in a loose sling. SQ 29,548 or vehicle control was prepared by dissolution in $95 \%$ ethanol $(10 \mathrm{~g} / \mathrm{L})$ and addition of $2 \mathrm{mM} \mathrm{Na} \mathrm{CO}_{3}$ until the final concentration of SQ $29,5481 \mathrm{~g} / \mathrm{L}$ was obtained. After at least $1 \mathrm{~h}$ of baseline measurement, SQ 29,548 or vehicle control was started as an i.v. bolus of $2 \mathrm{mg} / \mathrm{kg}$ followed by a continuous infusion of $2 \mathrm{mg} / \mathrm{kg} /$ h. This infusion rate of SQ 29,548 had previously been shown

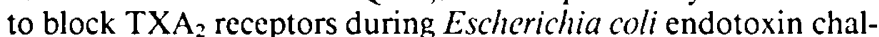
lenge in sheep (16). After another hour of baseline measurements, $38 \mathrm{pmol}$ of GBS toxin per kilogram mixed in $30 \mathrm{~mL}$ of normal saline was infused i.v. during $12 \mathrm{~min}$. Each animal received an identical dose of GBS toxin for the SQ 29,548 and control experiment. The response to GBS toxin was monitored for $5 \mathrm{~h}$ after the beginning of GBS toxin infusion.

Hemodynamic measurements were performed every $15 \mathrm{~min}$ from the beginning of GBS toxin infusion until $1.5 \mathrm{~h}$ and at $30-$ min intervals thereafter. Lung mechanics and lung volume measurements were performed at $15,30,38,45$, and 60 min during the first hour and at 30-min intervals between 1 and $5 \mathrm{~h}$ after the start of GBS toxin infusion. Ventilatory parameters were measured every $30 \mathrm{~min}$ until $2 \mathrm{~h}$ and thereafter every hour. Arterial $\mathrm{PO}_{2}, \mathrm{PCO}_{2}, \mathrm{pH}$, and body temperature were measured at the same intervals. Measurements of white blood cell count, granulocytes, lymphocytes, and packed red cell volume (hematocrit) were obtained at $1,1.5,2,3,4$, and $5 \mathrm{~h}$. Measurements of
$\mathrm{TXB}_{2}$ and 6-keto-PGF $\mathrm{l}_{\mathrm{l}}$ in plasma were made hourly during the study. The animals were killed after completion of the studies.

The research protocol was approved by the Vanderbilt University Animal Care Committee.

Hemodynamic measurements. Mean pressures were continuously recorded from the pulmonary artery $\left(P_{P_{A}}\right)$, left atrium $\left(P_{L \Lambda}\right)$, right atrium $(C V P)$, and aorta (MSP) by pressure transducers (model 1290A, Hewlett-Packard, Andover, MA). $P_{C w}$ was measured periodically through a $5 \mathrm{Fr}$ Swan-Ganz catheter placed in wedge position in the pulmonary artery. $\mathrm{CO}$ was continuously monitored via the electromagnetic flow cuff around the main pulmonary artery (Narcomatic flowmeter model RT-510, Narco Biosystems, Inc., Houston, TX). CO was normalized to body weight, and the normalized $\mathrm{CO}$ was used to calculate vascular resistance. Total PVR was calculated as $\left(\mathrm{P}_{\mathrm{PA}}-\mathrm{P}_{\mathrm{LA}}\right) / \mathrm{CO}$. PVR confined to the precapillary bed was calculated as $\left(\mathrm{P}_{\mathrm{PA}_{\mathrm{A}}}-\mathrm{P}_{\mathrm{CW}}\right) /$ $\mathrm{CO}$ and that confined to the postcapillary bed as $\left(\mathrm{P}_{\mathrm{CW}}-\mathrm{P}_{\mathrm{I.A}}\right) /$ $\mathrm{CO}$. Systemic vascular resistance was calculated as (MSP CVP)/CO.

Lung function measurements. The technique for measurements and calculations of lung function in this study has previously been evaluated and described in detail in lambs (17) and newborn infants (18). Ventilatory flow in the cuffed ET tube inserted through the tracheostoma was measured by a heated pneumotachograph (Hewlett-Packard, No. 0) connected to a pressure transducer (model MP 45-1-871, $\pm 2 \mathrm{~cm} \mathrm{H}_{2} \mathrm{O}$, Validyne Engineering Corp., Northridge, CA) and a carrier demodulator (model CO 1914, Validyne Engineering Corp.). Transpulmonary pressure was measured between the airway (the proximal part of the ET tube) and the pleural balloon (Silastic envelope) in the right pleural space by a pressure transducer (model MP 45-1$871, \pm 50 \mathrm{~cm} \mathrm{H}_{2} \mathrm{O}$ ) and a carrier demodulator. Nitrogen concentration in breathing gas was measured continuously in the proximal part of the ET tube by a nitrogen analyzer (model 505 Nitrolyzer, Med Science Electronic, Inc., St. Louis, MO). A system of tubing (dead space $7 \mathrm{~mL}$ ) was connected to the lamb's ET tube with a continuous bypass flow with a positive endexpiratory pressure of $4 \mathrm{~cm} \mathrm{H}_{2} \mathrm{O}$. Multiple-breath nitrogen washout tests were performed during $100 \%$ oxygen breathing to measure FRC and ventilatory parameters. The ventilatory flow, pressure, and nitrogen signals were all sampled into a portable computer unit (NEC, Portable Powermate, NEC Technology, Boxborough, MA) and a 12-bit analog-digital converter (model DT 280, Data Translation, Marlborough, MA) with a sample rate of $200 \mathrm{~Hz}$ for further calculations. Lung $C_{d y n}$ and $R_{1}$ were calculated from the sampled ventilatory flow and transpulmonary pressure signals. The computerized system for calculation of lung mechanics has previously been described in detail (19, 20).

FRC was calculated by dividing the expired lung nitrogen volume by the end tidal nitrogen concentration before the initiation of oxygen breathing. FRC was normalized to body weight. From the nitrogen lung volume elimination curve, a dilution factor that made it possible to estimate ventilatory dead space and alveolar ventilation could be derived. A lung model was used to describe the nitrogen elimination pattern (distribution of ventilation) by fitting one, or the sum of two or three, exponential equations to the lung nitrogen elimination curve (21). The number of equations giving the best least-square fit to the original washout curve was chosen as the best description of the nitrogen elimination pattern (distribution of ventilation). Not all nitrogen washout curves could be satisfactorily described by this exponential lung model, such as when the exponential estimate deviated too much from the original lung nitrogen elimination curve.

The gas mixing efficiency of the ventilatory system was calculated as an NC index. NC index was defined as the ventilatory volume necessary to dilute the nitrogen lung volume from 90 to $10 \%$ of its total value, divided by the FRC.

Laboratory analysis. Arterial blood gas determinations were made using a model $158 \mathrm{pH} /$ blood gas analyzer (Ciba Corning 
Diagnostic Corp., Medfield, MA). White blood cells were counted with a model ZBI Coulter counter (Coulter Electronics, Hialeah, FL) specifically adjusted for counting sheep cells. A blood smear was stained with Wright's stain to determine the number of granulocytes and lymphocytes per 100 white cells. Analysis of $\mathrm{TXB}_{2}$ and 6-keto-PGF $\mathrm{F}_{\mathrm{l}}$ in plasma was performed in duplicate using an enzyme immunoassay method $(22,23)$ with $\mathrm{MAb}$, anti-IgG antibodies, enzymatic tracers, and specific eicosanoid antisera obtained from Cayman Chemicals (Ann Arbor, $\mathrm{MI})$.

$T X$ agonist. Before each study was completed, the efficacy of SQ 29,548 as a TX receptor antagonist was tested by an i.v. injection of the TX agonist 9,11-dideoxy-1 $1 \alpha, 9 \alpha$-epoxymethano$\mathrm{PGF}_{2 \alpha}$ (U 46,619, Upjohn Company, Kalamazoo, MI) in a dose of $5 \mu \mathrm{g} / \mathrm{kg}$. An average increase in $P_{\mathrm{PA}}$ of $2.5 \mathrm{~mm} \mathrm{Hg}$ occurred when the agonist was given during SQ 29,548 treatment, whereas an average increase in $\mathrm{P}_{\mathrm{PA}}$ of $54 \mathrm{~mm} \mathrm{Hg}$ was observed in the control study.

Isolated effect of SQ 29,548. The isolated effect of SQ 29,548 on all physiologic variables was tested in three separate lambs that were 18 to $25 \mathrm{~d}$ old. These lambs were instrumented in the same way as those included in the study. We found no isolated effect by SQ 29,548 on any of the measured variables during a 6-h study period, preceded by $2-\mathrm{h}$ baseline measurements, except for a marginal decline in total PVR.

Statistics. We assessed the effect of SQ 29,548 within a period by using a repeated measures analysis of variance when all data were available. The repeated measures analysis of variance combines all data for a period into a single statistical test of the effect of treatment in a period. When some data were missing, we averaged the difference between SQ 29,548 and control for each time available for an animal and then tested whether this average difference was significantly different from zero. This is algebraically equivalent to the test used in the repeated measures analysis of variance when data are complete. Repeated measures analysis of variance was used to determine overall treatment effect during the whole 5-h study period and during each phase of the GBS toxin reaction separately.

To show how results changed from baseline within a treatment arm or between groups at a single time point, we used paired $t$ tests and show these results in the figures and tables. The results of these tests are intended to help clarify when differences between groups are most pronounced. The results of the individual tests at specific time points are not used in determining whether there is an overall difference between the two treatment arms.

We claim an overall treatment effect only if repeated measures analysis of variance (or the equivalent single test of treatment effect when data were incomplete) showed a statistically significant difference at $p<0.05$ for the whole 5-h study period. A significant effect in an individual phase of the GBS toxin response is based on the repeated measures analysis of variance (or equivalent test) for that phase.

\section{RESULTS}

Biphasic response. In general, the vascular changes after GBS toxin infusion showed a biphasic response where the phases showed different characteristics. The first phase of the reaction $(0.25$ to $1.5 \mathrm{~h})$ reached its peak 30 to $60 \mathrm{~min}$ after the beginning of toxin infusion. The second phase of the reaction ( 2 to $5 \mathrm{~h}$ ) reached its maximum after 2 to 3 hours.

$P_{P_{A}}, P_{C W}$, and $P_{L A}$ (Fig. 1). $P_{P_{A}}$ and $P_{C W}$ in the control study showed a typical biphasic response with a significant increase in pressure compared with baseline. The first phase showed the highest pressure increase but with shorter duration compared with the second phase. There was a significant overall treatment effect by SQ 29,548 during the whole study period $(p<0.01$ repeated measures analysis of variance), mostly because of the significant treatment effect in the first phase $(p<0.001$, not adjusting for possible baseline difference: $p<0.01$, adjusted for

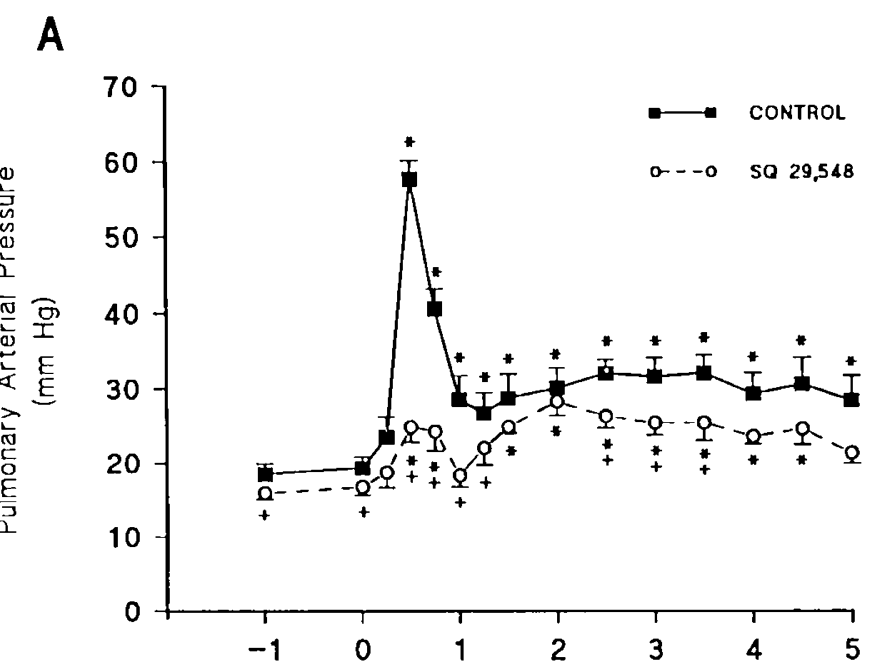

B

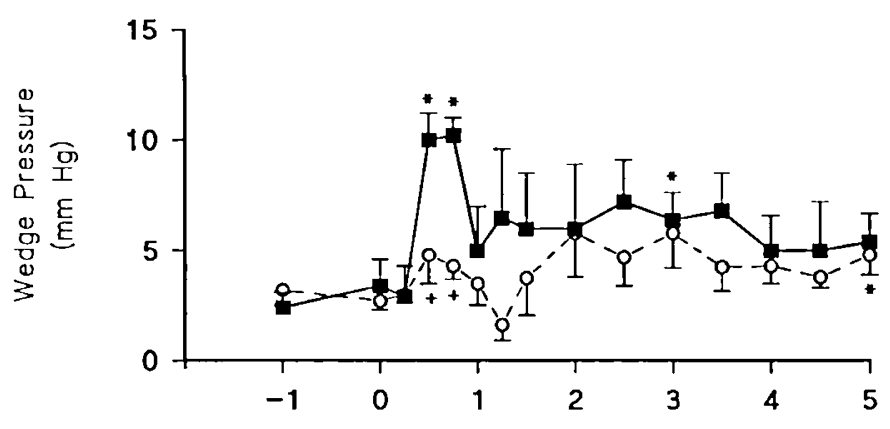

C

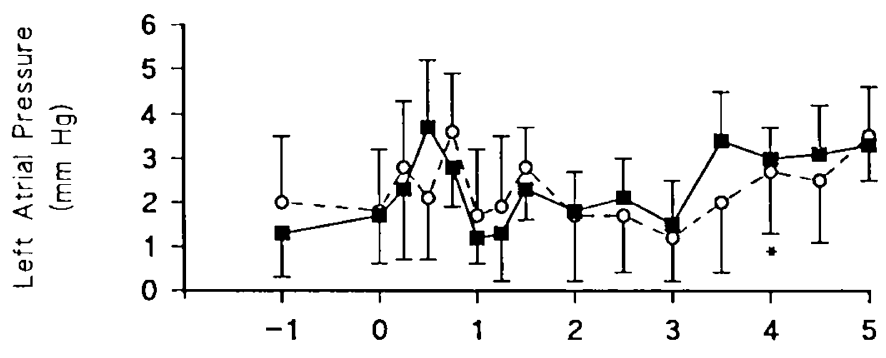

TIME AFTER GBS TOXIN (h)

Fig. 1. $A, \mathrm{P}_{\mathrm{PA}}: B, \mathrm{P}_{\mathrm{Cw}} ; C, \mathrm{P}_{\mathrm{LA}}$ in six young lambs during a control study and during SQ 29.548 treatment. Values are mean \pm SEM. *, Significant difference (paired $t$ test, $p<0.05$ ) between individual time points and baseline value at zero time. + , Significant difference (paired $t$ test. $p<0.05$ ) between groups at an individual time point. Repeated measures analysis of variance showed a significant treatment effect on $\mathrm{P}_{\mathrm{PA}}(p<0.01$ overall; $p<0.0001$ first phase $)$ and $\mathrm{P}_{\mathrm{CW}}(p<0.05$ first phase).

baseline). The treatment effect during the second phase was statistically significant with use of the unadjusted baseline $(p<$ 0.05 ). If adjustment was made for the possible difference at baseline, this effect was no longer statistically significantly different. Pulmonary $P_{C w}$ was significantly lower with SQ 29,548 only during the first phase $(p<0.05$, repeated measures analysis of variance). $P_{L A}$ did not change significantly over time, nor was the response different in the presence of SQ 29,548.

Heart rate, $C O$, and stroke volume (Fig. 2). There was no overall treatment effect on heart rate during the study on the basis of the repeated measures analysis of variance. However, in the control study the animals showed a significant increase in heart rate late in the first phase and during the second phase of the reaction, whereas after SQ 29.548 treatment the animals 
A
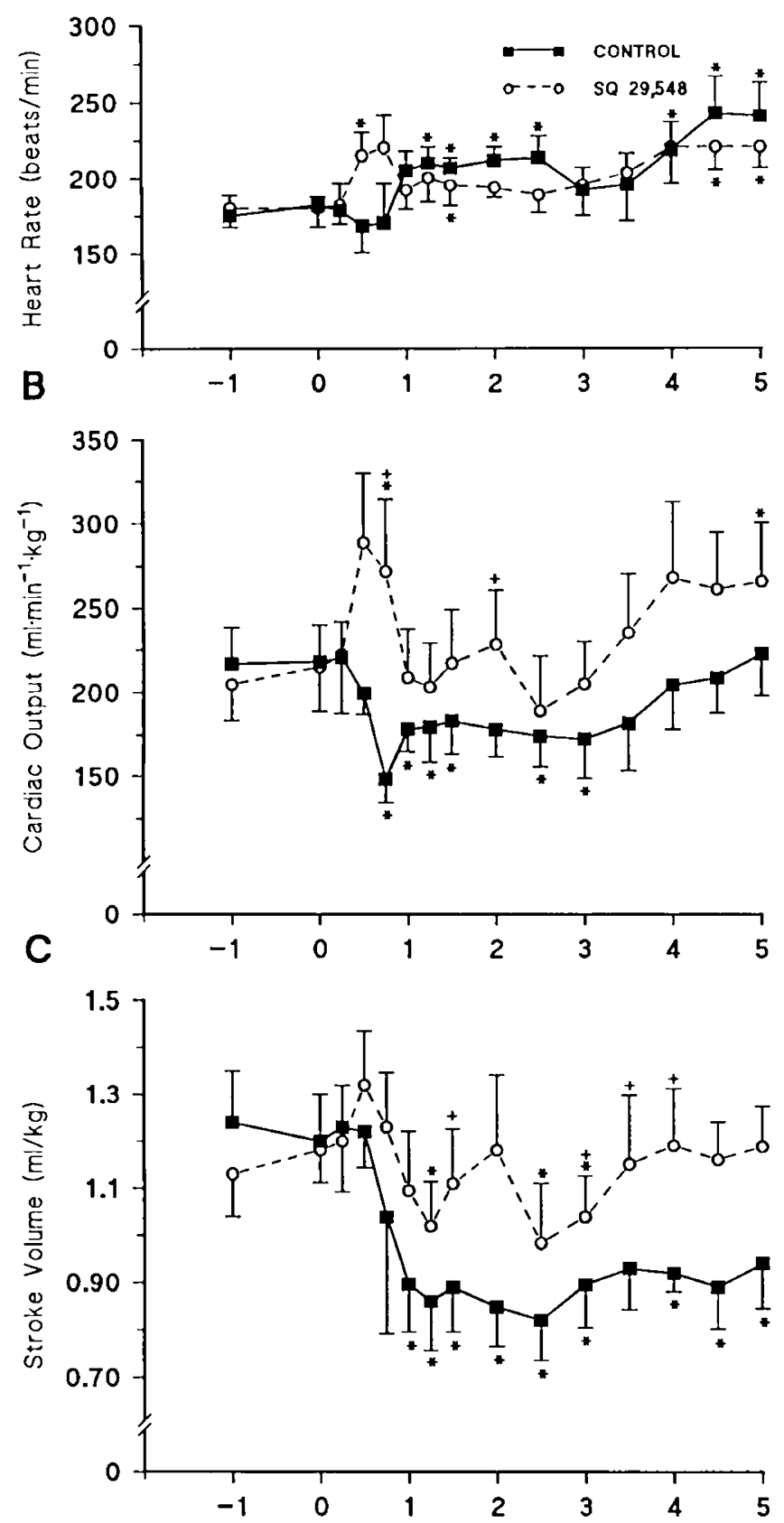

TIME AFTER GBS TOXIN (h)

Fig. 2. $A$, Heart rate; $B$, $\mathrm{CO} C C$, stroke volume in six young lambs during a control study and during SQ 29,548 treatment. Values are mean \pm SEM. ${ }^{*}$, Significant difference $(t$ test, $p<0.05$ ) between individual time points and baseline value at zero time. + , Significant difference (paired $t$ test, $p<0.05$ ) between groups at an individual time point. Repeated measures analysis of variance showed a significant treatment effect on stroke volume ( $p<0.05$ overall; $p<0.01$ first phase; $p<0.05$ second phase).

responded sooner with modest tachycardia during both the first and second phase of the toxin reaction. $\mathrm{CO}$ decreased significantly compared with baseline $45 \mathrm{~min}$ after the beginning of the toxin infusion and remained significantly decreased until after 3 $\mathrm{h}$ in the control study. After SQ 29,548 treatment, the animals not only managed to preserve their $\mathrm{CO}$ but also showed a significant increase during the first phase of the reaction. The overall treatment effect on CO by SQ 26,548 during the whole study was marginally significant $(p=0.06$, repeated measures analysis of variance). The decrease in $\mathrm{CO}$ in the control study was mainly caused by a significant reduction in stroke volume, which stayed low during the whole reaction. During SQ 29,548 treatment, the stroke volume was largely preserved. The difference in stroke volume was significant over the entire period $(p$ $<0.05)$, in particular during the first phase $(p<0.01$; second phase, $p<0.05$ ).

MSP, CVP, and vascular resistance (Fig. 3). MSP was higher in the control study compared with the SQ 29,548 study during the first phase of the reaction $(p<0.05)$ but similar in the second

A

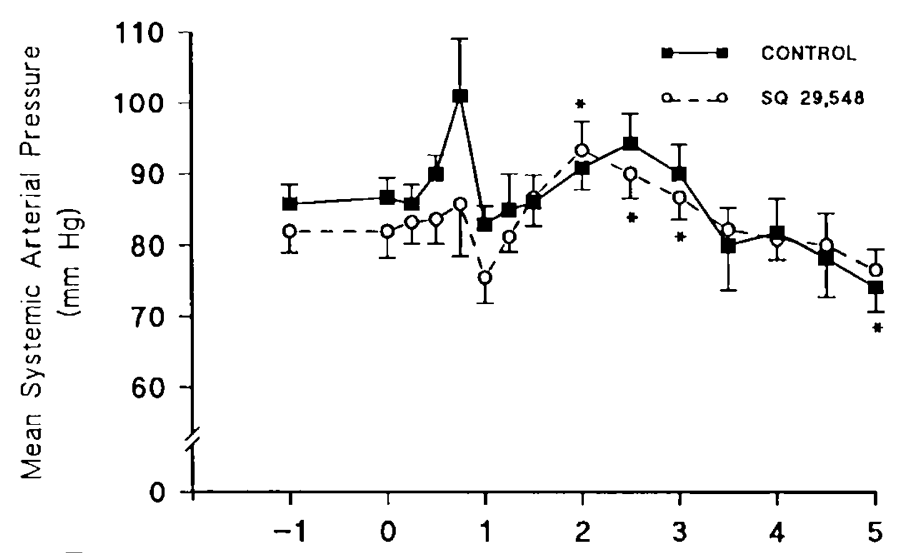

B
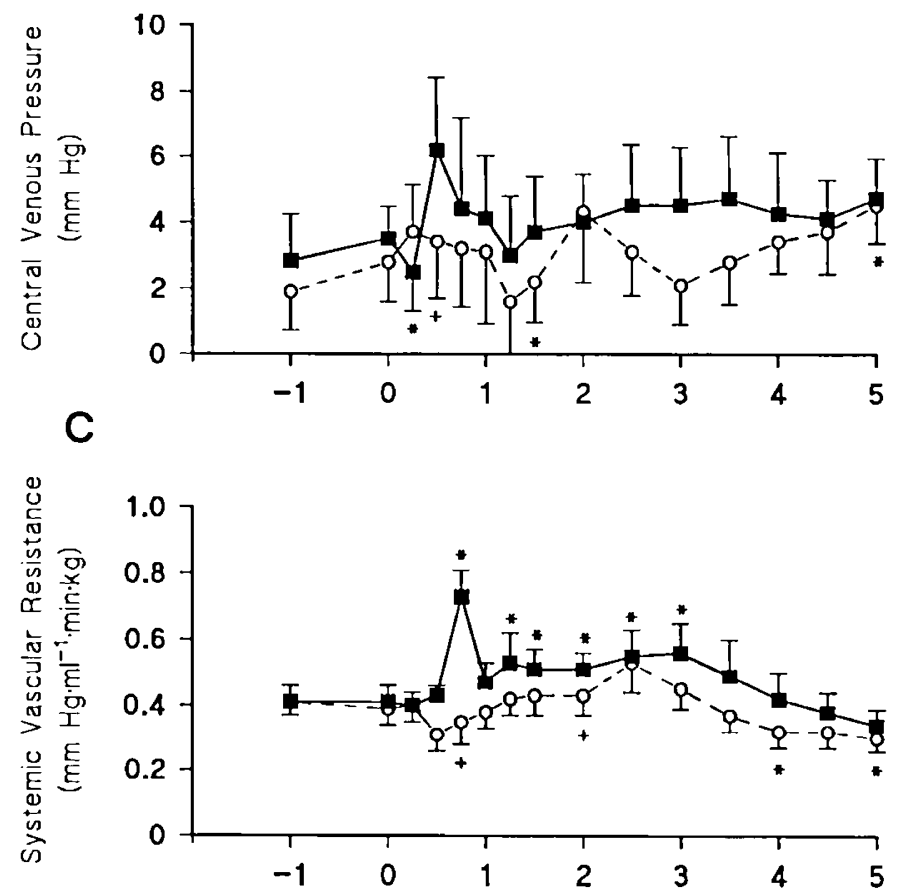

TIME AFTER GBS TOXIN (h)

Fig. 3. A, Mean systemic arterial pressure: $B, C V P ; C$, systemic vascular resistance for five lambs during a control study and during SQ 29,548 treatment. Values are mean \pm SEM. ${ }^{*}$, Significant difference (paired $t$ test. $p<0.05$ ) between individual time points and baseline value at zero time. + , Significant difference (paired $t$ test, $p<0.05$ ) between groups at an individual time point. Repeated measures analysis of variance showed significant treatment effects on mean systemic arterial pressure and systemic vascular resistance during the first phase after GBS toxin $(p<0.05)$. 
phase. No major changes were seen in CVP. Only at $30 \mathrm{~min}$ after the start of the toxin infusion was the CVP significantly higher in the control study compared with the SQ 29,548 study.

Systemic vascular resistance increased significantly in the control study but not after SQ 29,548 treatment. The two studies were significantly different in the first phase $(p<0.05)$.

PVR (Fig. 4). The major treatment effects of SQ 29,548 were seen on the PVR. In the control study, total PVR significantly increased compared with baseline during both the first and

\section{A}
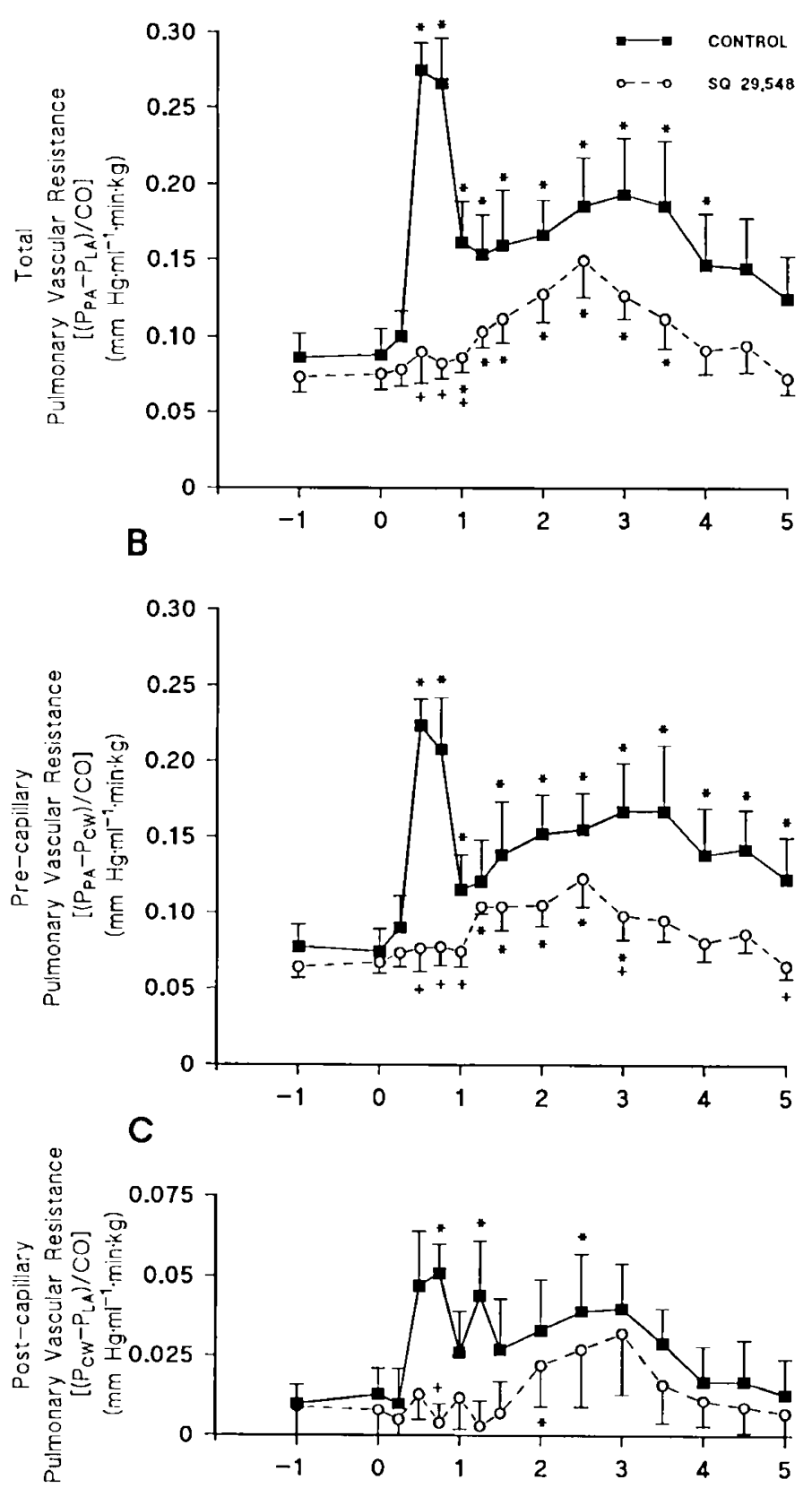

TIME AFTER GBS TOXIN (h)

Fig. 4. A, Total PVR: $B$, PVR in precapillary vascular bed; $C$, PVR in postcapillary vascular bed in six young lambs during a control study and during SQ 29.548 treatment. Values are mean \pm SEM. *, Significant difference (paired $t$ test, $p<0.05$ ) between individual time points and baseline value at zero time. + . Significant difference (paired $t$ test, $p<$ 0.05 ) between groups at an individual time point. Repeated measures analysis of variance showed a significant treatment effect on total PVR and precapillary PVR (both $p<0.05$ overall, $p<0.01$ first phase). second phase of the reaction. The increase in resistance was higher with shorter duration during the first phase compared with the second phase. Although PVR also increased with SQ 29,548 , the increase was later and much smaller and there was an overall treatment effect of SQ $29.548(p<0.05)$ during the whole study period, mainly because of a highly significant treatment effect during the first phase of the reaction $(p<0.01$; second phase, $p>0.1$ ). The PVR increase during the first phase of the toxin reaction was abolished by the treatment.

A significant increase compared with baseline in PVR was found on both sides of the capillary bed in the lung in the control study. The major PVR change was in the arterial part of the pulmonary circulation, but there were also increases on the venous side. Treatment with SQ 29,548 substantially altered PVR on both sides of the capillary bed, but the treatment effect was statistically significant only in the precapillary bed $(p<0.05$ overall, $p<0.01$ in phase 1). The major effect was during the first phase of the reaction that was completely blunted.

Lung mechanics (Fig. 5). After GBS toxin infusion in the control study, there was a significant decrease in $\mathrm{C}_{\mathrm{dyn}}$ compared with baseline during the first phase of the reaction. This decrease in $C_{d y n}$ coincided with the increase in $P_{P A}$ and PVR. After SQ 29,548 treatment, no significant changes in $C_{d y n}$ were observed. There was a significant overall treatment effect $(p<0.05)$ by the blocker mainly because of the difference in the first phase $(p<$ 0.05 ; second phase, $p>0.1$ ). Calculations of specific compliance $\left(C_{\text {dyn }} / F R C\right)$ also showed that SQ 29.548 completely blocked the reaction by the toxin during the first phase (data not shown). No significant respiratory rate dependence on the measurements of $\mathrm{C}_{\text {dyn }}$ could be found.

The changes in $R_{1}$ showed a biphasic response with significant increase compared with baseline in $R_{1}$ during both the first and second phase in the control study. After SQ 29,548 treatment, the changes in $R_{1}$ persisted but to a lesser extent. However, there was no statistical evidence that SQ 29,548 affected $R_{1}$ response after GBS toxin. Calculations of specific conductance $\left(1 \cdot R_{1}^{-1}\right.$. $F R C^{-1}$ ) did not reveal a statistically significant treatment effect by SQ 29,548 on the airway reactivity to GBS toxin infusion (data not shown).

FRC (Fig. 5). No significant difference was found in FRC between the treatment and control studies. A tendency toward an increase in FRC during the study compared with baseline was found after SQ 29,548 treatment, whereas after an initial small increase no FRC changes were found in the control study.

Ventilation (Table l). An increase from baseline in both total and alveolar ventilation (calculated from the nitrogen washout curve) was found in both studies but was more prominent early during the toxin challenge. No treatment effect by SQ 29,548 was found on ventilation.

Gas mixing efficiency (NC index) was unaffected by GBS toxin infusion both with and without SQ 29,548 treatment. For estimation of the lung nitrogen elimination pattern (distribution of ventilation), a total of 92 curves in the control study and 90 curves in the SQ 29,548 study were subject to description by our exponential lung model (21). In the control study, $35 \%$ of the washout curves could best be described by a single exponential component, and a two-component model fit best in $40 \%$ of the curves. In $25 \%$ of the curves, exponential estimation of the washout pattern was unsatisfactory according to our lung model. The corresponding numbers in the SQ 29,548 study were $30 \%$ (one component), $43 \%$ (two components), and $27 \%$ (unsatisfactory description). No specific change in exponential patterns could be observed during the course of the studies, and there were no significant differences between the control and SQ 29,548 treatment.

Gas exchange and body temperature (Table 2). There was a significant decrease in oxygenation compared with baseline in the control study. There was a much smaller decrease with SQ 29,548 treatment $(p<0.05$ overall). This difference was most pronounced during the first phase of the reaction $(p<0.01)$ and 
A

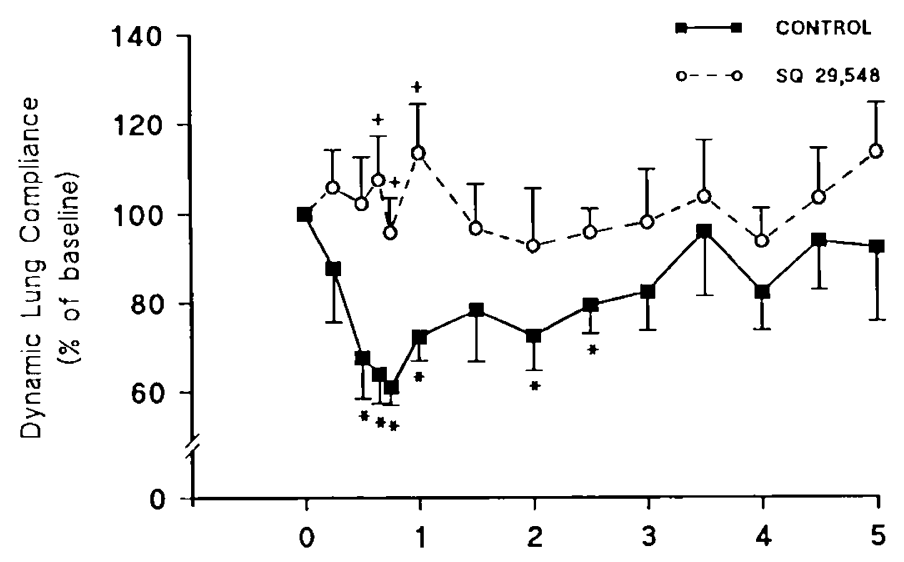

B

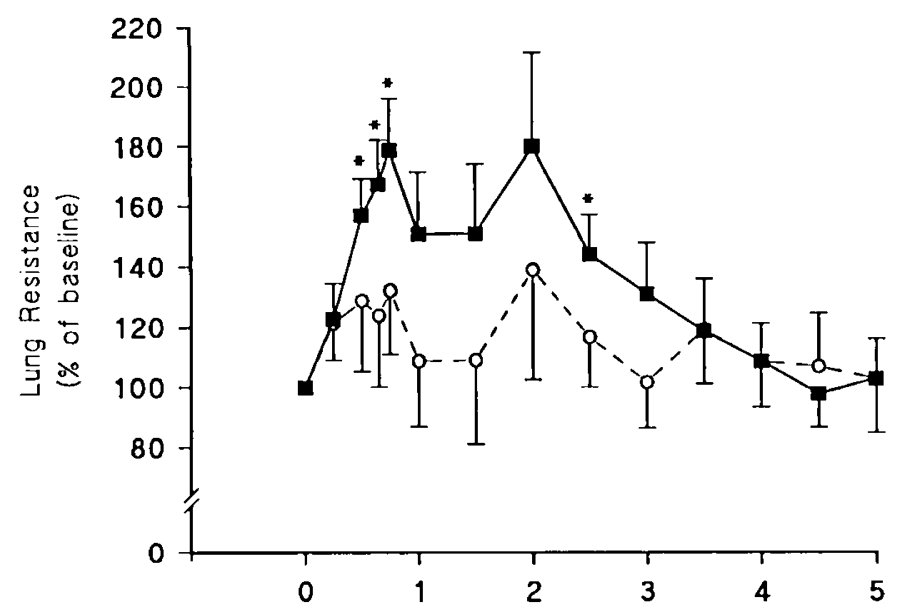

C

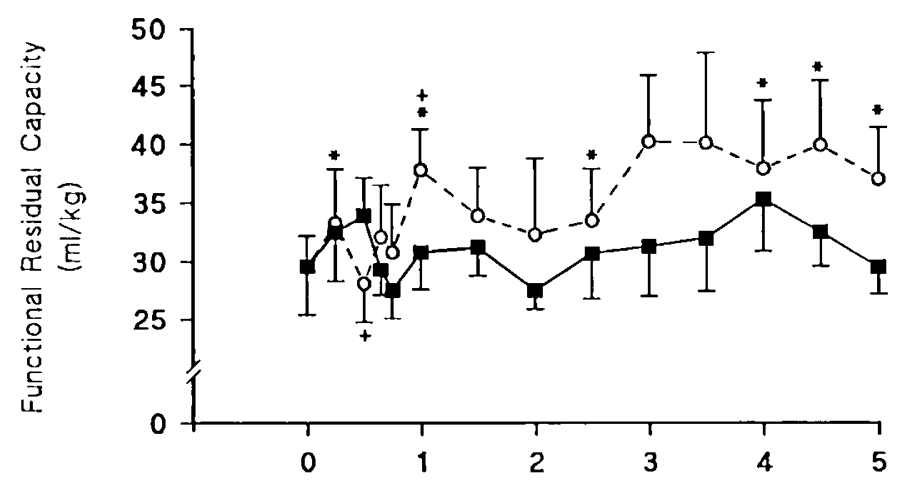

TIME AFTER GBS TOXIN (h)

Fig. 5. $A$, Lung $C_{\mathrm{dyn}} ; B, \mathrm{R}_{\mathrm{l}}$ to ventilatory flow: $C, \mathrm{FRC}$ in six young lambs during a control study and during SQ 29,548 treatment. Values are mean \pm SEM. ${ }^{*}$, Significant difference (paired $t$ test, $p<0.05$ ) between individual time points and baseline value at zero time. + , Significant difference (paired $t$ test, $p<0.05$ ) between groups at an individual time point. Repeated measures analysis of variance showed a significant treatment effect on $\mathrm{C}_{\mathrm{dyn}}(p<0.05$ overall, $p<0.05$ first phase).

coincided with the pulmonary vascular and lung mechanical changes (second phase, $p>0.1$ ). No significant changes or differences between the studies were observed in arterial $\mathrm{PCO}_{2}$ and base excess. The body temperature increased significantly during both control and SQ 29,548 studies in comparison with baseline.
White blood cells and packed red cell volume (Table 3). There was a significant decrease compared with baseline in white blood cell count after GBS toxin infusion in both studies. Both lymphocytes and granulocytes were affected. There was a statistically significant difference in total white blood cell count between the two studies in the second phase $(p<0.05)$. In the control study, some hemoconcentration occurred during both the first and second phase of the reaction, but a statistically significant difference compared with baseline in packed red cell volume was seen only during the second phase. There was no hemoconcentration during the first phase of the SQ 29,548 studies.

Prostaglandins (Table 4). $\mathrm{TXB}_{2}$ plasma concentration was significantly increased compared with baseline during the whole study period in both studies. There were no statistically significant differences in serum concentrations whether the animal was treated or not treated with SQ 29,548. The serum concentration of 6-keto-PGF $F_{1, x}$ showed a slight increase at 1 and $2 \mathrm{~h}$ after the toxin infusion. There was no significant difference between the studies.

\section{DISCUSSION}

This study showed that hemodynamic changes dominated after GBS toxin infusion, and these changes were mainly affected by the SQ 29,548 treatment. As has been described previously, the response to GBS toxin was biphasic $(10,11)$. In the pulmonary circulation, we found a significant increase in the $P_{P A}$ and PVR in the control study. Treatment of the animal with SQ 29,548 showed a significant treatment effect, abolishing the first phase of the pulmonary vascular reaction. Our results, linking $\mathrm{TXA}_{2}$ to pulmonary vasoconstriction during the first phase, support work performed by others (24-31). The second phase of the pulmonary vascular reaction was not significantly attenuated by SQ 29,548 treatment, suggesting that $\mathrm{TXA}_{2}$ is mainly involved in the first part of the response. The marked increase in serum concentration of $\mathrm{TXB}_{2}$ during the first phase compared with the second phase of the reaction is further support for this idea.

The isolated effect of a prolonged SQ 26,548 infusion was tested in three separate animals. Except for a marginal decline in total PVR, which did not affect the results of the study, we found no isolated effect on any physiologic variable that could be attributed only to SQ 29,548. Also, during baseline measurements before toxin infusion, no effect of SQ 29,548 could be observed. This means that the pathophysiologic differences noted in this study between control and SQ 29,548 treatment are most likely attributed to the effect of SQ 29.548 on changes induced by the GBS toxin rather than a direct effect of SQ 29,548 alone.

In previous histologic examinations of lung tissue after GBS toxin infusion, signs of severe blood congestion have been found $(2,10)$. An increase in the lung microvascular pressure due to venous constriction is the probable cause. We have previously shown that the flow of lung lymph with low protein concentration significantly increases in lambs during the first phase of the GBS toxin reaction $(11,12)$. An increase in pulmonary microvascular pressure is clearly implicated by the increased proteinpoor lymph flow rate during the first phase of the reaction. This increase in pulmonary microvascular pressure could be caused by an increase in pulmonary venous constriction. This has been extensively studied in the sheep model after $E$. coli endotoxin challenge (32). In that study, the fraction of the PVR attributed to the pulmonary veins was significantly increased during the toxin reaction. In our study, we also partitioned the response in PVR into precapillary and postcapillary compartments, which was not done previously in the GBS model. In the control study, the fraction of the total PVR, which could be attributed to an increase in venous constriction, was between 25 and $30 \%$ during both the first and second phase of the reaction, whereas the baseline value was about $15 \%$ of total PVR. This indicates that pulmonary venous tone is increased during the GBS toxin reaction. The increase in the fraction of the total PVR attributed to 
TXA $_{2}$ BLOCKADE IN GBS TOXIN CHALLENGE

Table 1. Ventilatory measurements (mean + SEM)*

\begin{tabular}{|c|c|c|c|c|c|c|c|c|c|}
\hline Time & Study & Bascline & $1 / 2 \mathrm{~h}$ & I h & $1 \frac{1}{2} \mathrm{~h}$ & $2 \mathrm{~h}$ & $3 \mathrm{~h}$ & $4 \mathrm{~h}$ & $5 \mathrm{~h}$ \\
\hline \multirow{2}{*}{$\begin{array}{l}\text { Breathing frequency } \\
\text { (breath } / \mathrm{min})\end{array}$} & CTL & $47 \pm 4.5$ & $56 \pm 5.6$ & $58 \pm 8.6$ & $58 \pm 7.3$ & $53 \pm 7.3$ & $61 \pm 10.6$ & $72 \pm 12.2$ & $63 \pm 6.0 \dagger$ \\
\hline & SQ & $46 \pm 4.1$ & $40 \pm 9.1$ & $51 \pm 2.6$ & $69 \pm 9.2$ & $54 \pm 6.5$ & $70 \pm 9.1 \dagger$ & $61 \pm 4.1 \dagger$ & $60 \pm 9.3$ \\
\hline \multirow[t]{2}{*}{ Tidal volume $(\mathrm{mL} / \mathrm{kg})$} & CTL & $5.7 \pm 0.4$ & $6.1 \pm 0.8$ & $6.5 \pm 0.9$ & $6.7 \pm 0.8$ & $6.6 \pm 0.7$ & $6.5 \pm 0.7$ & $5.1 \pm 0.4$ & $5.3 \pm 0.4$ \\
\hline & SQ & $5.9 \pm 0.5$ & $6.7 \pm 0.8$ & $5.3 \pm 0.4$ & $5.6 \pm 0.4$ & $6.2 \pm 0.6$ & $5.3 \pm 0.4$ & $5.4 \pm 0.6$ & $5.7 \pm 0.5$ \\
\hline \multirow{2}{*}{$\begin{array}{l}\text { Total ventilation }(\mathrm{mL} / \\
\min / \mathrm{kg})\end{array}$} & CTL & $266 \pm 23$ & $347 \pm 59$ & $410 \pm 35 \dagger$ & $375 \pm 38 \dagger$ & $337 \pm 38$ & $376 \pm 44 \dagger$ & $374 \pm 66$ & $330 \pm 34 \uparrow$ \\
\hline & SQ & $260 \pm 18$ & $306 \pm 27$ & $361 \pm 55$ & $337 \pm 50$ & $345 \pm 45 \dagger$ & $358 \pm 38$ & $317 \pm 33$ & $301 \pm 25$ \\
\hline \multirow{2}{*}{$\begin{array}{l}\text { Alveolar ventilation } \\
(\mathrm{mL} / \mathrm{min} / \mathrm{kg})\end{array}$} & $\mathrm{CTL}$ & $114 \pm 12$ & $185 \pm 57$ & $177 \pm 29$ & $163 \pm 17 \dagger$ & $139 \pm 7$ & $153 \pm 17$ & $135 \pm 23$ & $117 \pm 8$ \\
\hline & SQ & $104 \pm 13$ & $150 \pm 28$ & $163 \pm 19 \dagger$ & $137 \pm 16$ & $128 \pm 15$ & $133 \pm 17 \dagger$ & $147 \pm 21$ & $123 \pm 14$ \\
\hline \multirow[t]{2}{*}{ NC index } & $\mathrm{CTL}$ & $6.4 \pm 0.4$ & $5.1 \pm 0.7$ & $5.8 \pm 0.4$ & $5.9 \pm 0.4$ & $6.2 \pm 0.5$ & $5.7 \pm 0.1$ & $7.6 \pm 0.6$ & $7.2 \pm 0.5$ \\
\hline & SQ & $7.3 \pm 1.1$ & $5.7 \pm 0.7$ & $5.6 \pm 0.5$ & $6.3 \pm 0.7$ & $6.9 \pm 1.1$ & $6.5 \pm 0.6$ & $6.8 \pm 0.8$ & $6.5 \pm 0.9$ \\
\hline
\end{tabular}

${ }^{*}$ CTL, control; SQ, SQ 29,548.

$+p<0.05$ compared with baseline.

Table 2. Gas exchange and body temperature (mean + SEM1)*

\begin{tabular}{|c|c|c|c|c|c|c|c|c|c|}
\hline Time & Study & Baseline & $1 / 2 h$ & $1 \mathrm{~h}$ & $1 \frac{1}{2 h}$ & $2 \mathrm{~h}$ & $3 \mathrm{~h}$ & $4 \mathrm{~h}$ & $5 \mathrm{~h}$ \\
\hline \multirow[t]{2}{*}{ Arterial $\mathrm{PO}_{2}(\mathrm{kPa})$} & CTL & $11.1 \pm 0.2$ & $7.9 \pm 0.5 \dagger$ & $8.6 \pm 0.9 \dagger$ & $9.8 \pm 0.4 †$ & $10.3 \pm 0.4 \dagger$ & $10.5 \pm 0.4$ & $9.6 \pm 0.5 \dagger$ & $9.8 \pm 0.5 \dagger$ \\
\hline & & & $10.0 \pm$ & & $10.6 \pm 0.5 \dagger$ & & & & 10.2 \\
\hline \multirow[t]{2}{*}{ Arterial $\mathrm{PCO}_{2}(\mathrm{kPa})$} & CTL & & & & $5.6 \pm 0.2$ & 5.1 & $5.0 \pm$ & & \\
\hline & SQ & & & & $5.3 \pm 0.1$ & $5.1 \pm$ & $5.2 \pm 0.2$ & $5.1 \pm 0.3$ & \\
\hline \multirow{2}{*}{$\begin{array}{l}\text { Base excess }(\mathrm{mEq} / \\
\text { L) }\end{array}$} & CTL & $0.9 \pm$ & $-1.4 \pm$ & $-7.0 \pm 3.6$ & $-4.6 \pm 3.0$ & $-4.3 \pm 2.5$ & $-3.9 \pm 2.8$ & $-2.0 \pm 3.0$ & $-1.5 \pm$ \\
\hline & SQ & $2.2 \pm 2.7$ & $0.4 \pm 2.1$ & $2.5 \pm 1.9$ & $1.7 \pm 1.6$ & $-0.4 \pm 1.5$ & $0.7 \pm 1.8$ & $1.2 \pm 2.5$ & $3.1 \pm$ \\
\hline \multirow{2}{*}{$\begin{array}{l}\text { Body temperature } \\
\left({ }^{\circ} \mathrm{C}\right)\end{array}$} & CTL & $39.6 \pm 0.2$ & $40.0 \pm 0.1 \dagger$ & $40.3 \pm 0.2 \dagger$ & $40.1 \pm 0.2 \dagger$ & $40.1 \pm 0.3 \dagger$ & $40.6 \pm 0.3 \dagger$ & $40.2 \pm 0.3 \dagger$ & $39.8 \pm 0.4$ \\
\hline & SQ & $39.3 \pm 0.2$ & $39.6 \pm 0.2 \dagger$ & $40.6 \pm 0.1 \dagger$ & $40.0 \pm 0.1 \dagger$ & $39.8 \pm 0.3 \dagger$ & $39.9 \pm 0.3+s$ & $39.4 \pm 0.2 \$$ & $39.3 \pm 0.2$ \\
\hline
\end{tabular}

* CTL, control; SQ, SQ 29,548.

$\dagger p<0.05$ compared with baseline.

$\ddagger$ Treatment effect $(p<0.05$ overall; first phase, $p<0.01)$.

$\S p<0.05$ between CTL and SQ at that time.

Table 3. Changes in blood cells (mean + SEMI)*

\begin{tabular}{|c|c|c|c|c|c|c|c|c|}
\hline Time & Study & Baseline & $1 \mathrm{~h}$ & $11 / 2 \mathrm{~h}$ & $2 \mathrm{~h}$ & $3 \mathrm{~h}$ & $4 \mathrm{~h}$ & $5 \mathrm{~h}$ \\
\hline White blood cell & $\mathrm{CTL}$ & $10893 \pm 1095$ & $3244 \pm 719 \dagger$ & $3859 \pm 618 \dagger$ & $3539 \pm 671 \dagger$ & $3738 \pm 950 \dagger$ & $4272 \pm 891 \dagger$ & $5277 \pm 1257 \dagger$ \\
\hline $\begin{array}{l}\text { count (cells/ } \\
\mathrm{mm}^{3} \text { ) }\end{array}$ & $\mathrm{SQ} \ddagger$ & $10685 \pm 1555$ & $6659 \pm 2525 \dagger$ & $6532 \pm 1332$ & $6771 \pm 1045$ & $5621 \pm 671+\$$ & $5829 \pm 788 \dagger$ & $7505 \pm 1114 \$$ \\
\hline $\begin{array}{l}\text { Granulocytes } \\
\left(\text { cells } / \mathrm{mm}^{3}\right)\end{array}$ & CTL & $5091 \pm 737$ & $432 \pm 297 \dagger$ & $1013 \pm 303 \dagger$ & $821 \pm 218 \dagger$ & $2279 \pm 828 \dagger$ & $2779 \pm 662 \dagger$ & $3236 \pm 741$ \\
\hline Lymphocytes & $\begin{array}{l}\text { SQ } \\
\text { CTL }\end{array}$ & $\begin{array}{l}4519 \pm 1191 \\
5802 \pm 1152\end{array}$ & $\begin{array}{l}2250 \pm 1276 \dagger \\
2804 \pm 471+\end{array}$ & $\begin{array}{l}2853 \pm 906 \\
2846 \pm 562\end{array}$ & $\begin{array}{l}3892 \pm 953 \S \\
2718 \pm 521 \dagger\end{array}$ & $\begin{array}{l}4105 \pm 863 \$ \\
1459 \pm 226 \dagger\end{array}$ & $\begin{array}{l}3977 \pm 845 \\
1483 \pm 234 \dagger\end{array}$ & $\begin{array}{l}5402 \pm 1322 \\
2283 \pm 840\end{array}$ \\
\hline (cells $\left./ \mathrm{mm}^{3}\right)$ & SQ & $6166 \pm 620$ & $4409 \pm 1253$ & $3660 \pm 675 \dagger$ & $2867 \pm 369 \dagger$ & $1493 \pm 282 \dagger$ & $1832 \pm 258 \dagger$ & $2093 \pm 417 \dagger$ \\
\hline $\begin{array}{c}\text { Packed red cell } \\
\text { volume }(\%)\end{array}$ & $\begin{array}{l}\text { CTL } \\
\text { SQ }\end{array}$ & $\begin{array}{l}27 \pm 1.5 \\
28 \pm 2.7\end{array}$ & $\begin{array}{l}30 \pm 2.4 \\
28 \pm 2.5\end{array}$ & $\begin{array}{l}28 \pm 2.4 \\
27 \pm 2.3\end{array}$ & $\begin{array}{l}29 \pm 1.9 \dagger \\
29 \pm 2.3\end{array}$ & $\begin{array}{l}30 \pm 2.1 \dagger \\
29 \pm 2.5+\end{array}$ & $\begin{array}{l}28 \pm 2.2 \\
29 \pm 2.9\end{array}$ & $\begin{array}{l}27 \pm 2.2 \\
26 \pm 2.4\end{array}$ \\
\hline
\end{tabular}

* CTL, control: SQ, SQ 29,548.

$\dagger p<0.05$ compared with baseline.

$\ddagger$ Treatment effect $(p<0.05$ second phase).

$\S p<0.05$ between CTL and SQ at that time.

Table 4. Plasma prostaglandins concentrations (mean $+S E M)^{*}$

\begin{tabular}{|c|c|c|c|c|c|c|c|}
\hline Time & Study & Baseline & $1 \mathrm{~h}$ & $2 \mathrm{~h}$ & $3 \mathrm{~h}$ & $4 \mathrm{~h}$ & $5 \mathrm{~h}$ \\
\hline \multirow[t]{2}{*}{$\mathrm{TXB}_{2}(\mathrm{ng} / \mathrm{L})$} & CTL & $117 \pm 25$ & $2687 \pm 1001$ & $1169 \pm 337 \dagger$ & $796 \pm 227 \dagger$ & $474 \pm 115 \dagger$ & $323 \pm 61 \dagger$ \\
\hline & SQ & $107 \pm 27$ & $1111 \pm 249 \dagger$ & $554 \pm 89 \dagger$ & $341 \pm 55 \dagger$ & $270 \pm 57 \dagger$ & $302 \pm 80 \dagger$ \\
\hline \multirow[t]{2}{*}{ 6-keto-PGF $F_{1 \alpha}(\mathrm{ng} / \mathrm{L})$} & CTL & $163 \pm 27$ & $781 \pm 396$ & $732 \pm 357$ & $222 \pm 72$ & $150 \pm 32$ & $172 \pm 55$ \\
\hline & SQ & $129 \pm 25$ & $332 \pm 36 \dagger$ & $310 \pm 31 \dagger$ & $169 \pm 26$ & $102 \pm 16$ & $132 \pm 36$ \\
\hline
\end{tabular}

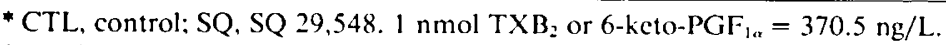

$\dagger p<0.05$ compared with baseline.

the venous side of the lung circulation was abolished during the first phase of the reaction during SQ 29,548 treatment. SQ 29,548 treatment may therefore reduce blood congestion of the lung and reduce hemoconcentration, which also occurs in the GBS toxic shock syndrome.

After toxin infusion in the control study, there was a significant decrease in $\mathrm{CO}$, which was caused by a significant reduction in stroke volume. The mechanism behind the cardiac decompensation in the control study could be secondary to hypovolemia and venous pooling, increased afterload, or a direct toxic effect on the myocardium mediated by $\mathrm{TXA}_{2}$ (33). Treatment with SQ
29,548 preserved stroke volume during the whole study together with $\mathrm{CO}$. The increased $\mathrm{CO}$ during the first phase of the GBS toxin response during SQ 29,548 treatment may have been related to increased body temperature and absence of an increase in systemic vascular resistance.

During the control study, lung mechanics showed a marked decrease in $\mathrm{C}_{\mathrm{dyn}}$ during the first phase of the toxin reaction coinciding with the increase in PVR. No significant changes in $C_{d y n}$ were found after SQ 29,548 treatment. It is plausible that the main cause of the reduced $C_{d y n}$ during the first phase of the control study was interstitial edema and blood congestion due to 
pulmonary venous constriction and an increase in lung microvascular pressure. It is also plausible that SQ 29.548 prevented pulmonary blood congestion by reducing the pulmonary venous constriction, which improved the mechanical properties of the lung. The improved lung function due to SQ 29,548 treatment during the first phase of the reaction also resulted in significantly better oxygenation compared with that in the control study.

Other factors such as changes in lung volume and respiratory rate could explain a reduction of $\mathrm{C}_{\mathrm{dyn}}$ in the control study. However, FRC did not decrease and specific compliance $\left(\mathrm{C}_{\mathrm{dyn}} /\right.$ FRC) also showed a reduction during the first phase in the control study (data not shown). Uneven distribution of ventilation in combination with an increase in respiratory rate might cause a decrease in $\mathrm{C}_{\mathrm{dyn}}$. This is probably not the case here, because we found no change in the distribution of ventilation according to our lung model and no significant correlation between respiratory rate and decrease in $\mathrm{C}_{\mathrm{dyn}}$ in either study. Furthermore, the NC index, which is supposed to reflect the gas mixing efficiency and the conditions in the small airways ( 34 , 35 ), was not affected during either the control or the SQ 29,548 study; this favors uncompromised patency of alveoli and peripheral airways.

In this study, we also found a biphasic increase in resistance to ventilatory flow similar to what we found in a previous study (11). Even if there was an attenuation of $R_{1}$ after SQ 29,548 treatment, this effect was not statistically significant. This means that $\mathrm{TXA}_{2}$ is not the only mediator of the smooth muscle constriction of the proximal airways. In this study, the proximal airway constriction with increased $R_{1}$ seemed to have little or no influence on ventilation, because FRC and gas mixing efficiency (as judged by the NC index) were unaffected in both studies. Total ventilation and alveolar ventilation, however, were increased both in the control study and after SQ 29,548 treatment. This probably reflects the increased metabolic demand at increased body temperature induced by the GBS toxin infusion.

During the second phase of the reaction, we found a significantly smaller decrease in total white blood cell count during the SQ 29,548 study compared with the control study, which could indicate reduced sequestration of white blood cells in the lung (10). SQ treatment may therefore also indirectly attenuate granulocyte-mediated lung injury (12).

In conclusion, treatment with a selective antagonist of the $\mathrm{TXA}_{2}$-prostaglandin endoperoxide receptor (SQ 29,548) in the GBS toxin lamb model primarily blocked the pathophysiologic changes during the first phase of the toxin reaction, demonstrat-

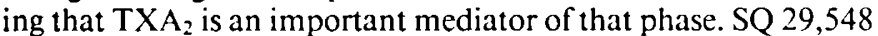
treatment led to significant reduction in the changes in pulmonary and systemic vascular resistance, improved $\mathrm{CO}$ and stroke volume, improved dynamic lung compliance, and improved oxygenation. TX receptor antagonists, such as SQ 29,548, may offer a potential therapeutic approach to infants with severe early-onset GBS sepsis. We propose that this should be investigated in animal models and humans with ongoing GBS sepsis.

Acknowledgments. The authors thank Stanley Poole, M.S.; Patricia Minton, R.N.; and Rao Gaddipati, M.S., for their skilled technical assistance; Dr. Brian Christman and Gayle King for performing prostaglandin determinations; and Donna Staed for typing the manuscript. We are also obliged to Dr. Martin Ogletree of E.R. Squibb Institute for Medical Research for providing the supply of SQ 29,548 and the Upjohn Company for providing $U$ 46,619 .

\section{REFERENCES}

1. Weisman LE, Stoll BJ, Cruess DF, Hall RT, Nerenstein GB, Hemming VG, Fisher GW 1992 Early-onset group B streptococcal sepsis: a current assessment. J Pediatr 121:428-433

2. Sundell HW, Fish WG, Sandberg KL, Edberg KE, Pappas RS, Hellerqvist CG 1990 Lung injury by streptoccal toxin. In: Brigham KL, Stahlman MT (eds)
Respiratory Distress Syndromes: Molecules to Man. Vanderbilt University Press, Nashville, TN. pp 58-70

3. Meadow WL, Meus PJ 1986 Early and late hemodynamic consequences of group B beta streptococcal sepsis in piglets: effects on systemic, pulmonary and mesenteric circulations. Circ Shock 19:347-356

4. Said SI, Foda HD 1989 Pharmacologic modulation of lung injury. Am Rev Respir Dis 139:1553-1564

5. Hellerqvist CG, Rojas J, Green RS. Sell S, Sundell H, Stahlman MT 1981 Studies on group B $\beta$-hemolytic streptococcus. I. Isolation and partial characterization of an extracellular toxin. Pediatr Res 15:892-898

6. Hellerqvist CG 1991 Therapeutic agent and method of inhibiting vascularization of tumors. Official Gazette/US Patent Trademark Oflices, Patents Vol 11/25 (April 23, 1991). US Patent 5.010,062

7. Hellerqvist CB, Sundell H, Gettins P 1987 Molecular basis for group B $\beta$ hemolytic streptococcal disease. Proc Natl Acad Sci USA 84:51-55

8. Hellerqvist CG, Thurman GB, Page DL. Wang YF, Russell BA, Montgomery CA. Sundell HW 1993 Anti-tumor effects of GBS toxin: a polysaccharide exotoxin from group B $\beta$-hemolytic streptococcus. Cancer Res Clin Oncol 120:63-70

9. Rojas J, Green RS, Hellerqvist CG, Olegaird R, Brigham KL, Stahlman MT 1981 Studies on group B $\beta$-hemolytic streptoccocus. II. Effects on pulmonary hemodynamics and vascular permeability in unanesthetized sheep. Pediatr Res 15:899-904

10. Rojas J, Larsson LE, Hellerqvist CG, Brigham KL, Gray ME, Stahlman MT 1983 Pulmonary hemodynamic and ultrastructural changes associated with group B streptococcal toxemia in adult sheep and newborn lambs. Pediatr Res 17:1002-1008

11. Sandberg KL. Englehardt B. Hellerqvist C. Sundell H 1987 Pulmonary response to group B streptococcal toxin in young lambs. J Appl Physiol 63:2024-2030

12. Englehardt B, Sandberg K, Bratton D, Van den Abbeele A Grögaard J, Hellerqvist C. Sundell H 1987 The role of granulocytes in the pulmonary response to group B streptococcal toxin in young lambs. Pediatr Res 21:159165

13. Rojas J, Larsson LE. Ogletree ML, Brigham KL. Stahlman MT 1983 Effects of cyclooxygenase inhibition on the response to group B streptococcal toxin in sheep. Pediatr Res 17:107-110

14. Rojas J, Palme C, Ogletree ML, Hellerqvist CG, Brigham KL, Stahlman MT 1984 Effects of methylprednisolone on the response to group B streptococcal toxin in sheep. Pediatr Res 18:1141-1144

15. Ogletree ML, Harris DN, Greenberg R, Haslanger MF, Nakane M 1985 Pharmacological actions of SQ 29.548, a novel selective thromboxane antagonist. J Pharmacol Exp Ther 234:435-441

16. Kühl PG, Bolds JM, Loyd JE, Snapper JR, Fitzgerald GA 1988 Thromboxane receptor-mediated bronchial and hemodynamic response in ovine endotoxemia. Am J Physiol 254:R310-R319

17. Sandberg KL, Edberg KE, Benton W, Silberberg A. Sladek M. Sundell H 199 Surfactant improves gas mixing and alveolar ventilation in preterm lambs. Pediatr Res 30:181-189

18. Sandberg KL, Sjöqvist BA, Hjalmarson O, Olsson T 1987 Lung function in newborn infants with tachypnca of unknown causc. Pediatr Res 22.581-586

19. Hjalmarson O 1974 Mechanics of breathing in newborn infants with pulmonary disease. Acta Paediatr Scand Suppl 247:5-70

20. Silberberg A 1992 On Respiratory System Mechanics in Ventilated Newborn Infants. Technical Report No. 228. Chalmers University of Technology, Gothenburg. Sweden

21. Sjoqvist B, Sandberg K, Hjalmarson O, Olsson T 1986 Method for analyzing multiple breath nitrogen washouts. Med Biol Eng Comput 24:83-90

22. Pradelles P. Grassi J, Maclouf J 1985 Enzyme immunoassays of eicosanoids using acethylcholinesterase as label: an alternative to radioimmunoassay. Anal Chem 57:1170-1173

23. Westcott JY, Chang S, Balazy M, Stene DO, Pradelles P, Maclouf J, Voelkel NF, Murphy RC 1986 Analysis of 6-keto-PGF $1 . .5$-HETE, and $\mathrm{LTC}_{4}$ in rat lung: comparison of GC/MS, RIA, and EIA. Prostaglandins 32:857-873

24. Shook LA, Pauly TH, Marple SL, Horstman SJ, Tai HH, Bowdy BD, Gillespie MN 1990 Group B streptococcus promotes oxygen radical-dependent thromboxane accumulation in young piglets. Pediatr Res 27:349-352

25. Runkle B, Goldberg RN, Streitfeld MM, Clark MR, Buron E, Setzer ES Bancalari E 1984 Cardiovascular changes in group B streptococcal sepsis in the piglet: response to indomethacin and relationship to prostacyclin and thromboxane $A_{2}$. Pediatr Res 18:874-878

26. Peevy KJ, Panus P, Longenecker GL, Chartrand SA, Wiseman HJ, Boerth RC, Olson RD 1986 Prostaglandin synthetase inhibition in group B streptococcal shock: hematologic and hemodynamic effects. Pediatr Res 20:864866

27. Pinheiro JMB, Pitt BR, Gillis CN 1989 Roles of platelet-activating factor and thromboxane in group B streptococcus-induced pulmonary hypertension in piglets. Pediatr Res 26:420-424

28. Truog WE, Sorensen GK. Standaert TA, Redding GJ 1986 Effects of the thromboxane synthetase inhibitor, Dazmegrel (UK 38,485), on pulmonary gas exchange and hemodynamics in neonatal sepsis. Pediatr Res 20:48 1-486

29. Tarpey MN, Graybar GB, Lyrene RK, Godoy G, Oliver J, Gray BM, Philips JB 1987 Thromboxane synthesis inhibition reverses group B streptococcusinduced pulmonary hypertension. Crit Care Med 15:644-647

30. Truog WE, Gibson RL, Juul SE, Henderson WR, Redding GJ 1988 Neonata 
Group B streptococcal sepsis: effects of late treatment with Dazmegrel. Pediatr Res 23:352-356

31. Hammerman C, Komar K, Meadow W, Strates E 1988 Selective inhibition of thromboxane synthetase reduces group-b-beta-hemolytic-streptoccoci-induced pulmonary hypertension in piglets. Dev Pharmacol Ther 11:306-312

32. Parker RE, Brigham KL 1987 Effects of endotoxemia on pulmonary vascular resistances in unanesthetized sheep. J Appl Physiol 63:1058-1062
33. Bressack MA, Morton NS. Hortop J 1987 Group B streptococcal sepsis in the piglet: effects of fluid therapy on venous return, organ edema, and organ blood flow. Circ Res 61:659-669

34. Cumming G 1967 Gas mixing efficieney in the human lung. Respir Physiol 2:213-224

35. Engel L 1983 Gas mixing within the acinus of the lung. J Appl Physiol 54:609618

\section{Announcement}

\section{American Cancer Society \\ Cancer Control Career Development Award for Primary Care Physicians}

The American Cancer Society is pleased to announce the 1995 Cancer Control Career Development Award for Primary Care Physicians (CCCDA). This award is intended to develop academic leaders in primary care specialties emphasizing cancer control: family practice, general internal medicine, obstetrics and gynecology, and pediatrics. Through the CCCDA, the Society seeks to support individuals in supervised programs that will develop the candidate's clinical and teaching expertise and his/her capacity to perform independent clinical research in cancer control. It is anticipated that physicians trained under these awards will improve cancer control through involvement in primary care practice, education, and research activities related to cancer control.

Candidates for first year Cancer Control Career Development Awards for Primary Care Physicians may not have an academic rank above that of Assistant Professor and must not be tenured or be the section head (or equivalent) in his/her discipline. These awards are intended to support the early development of academic careers which place emphasis on cancer control; physicians with well-established careers and substantial research funding should not apply. In addition. candidates for these awards must be citizens or permanent residents of the United States.

This is a 2-year award. The stipend for the award is $\$ 25,000$ for the first year and $\$ 30,000$ for the second. The application deadline is August 15, 1994 for awards to begin July 1, 1995.

Brochures and applications will be available in March 1994. To request firther information or application materials, please contact the office of: Virginia Krawiec, MPA, Detection and Treatment Department, American Cancer Society, Inc., 1599 Clifton Road, NE, Atlanta, GA 30329-4251, telephone: 404-329-5734; fax: 404-325-1467. 